\title{
Encyclopedia of Information Ethics and Security
}

\author{
Quigley, M. (2007) (Ed.). Hershey, PA: Information Science Publishing. \\ (ISBN-10: 159140987X \& ISBN-13: 978-1591409878)
}

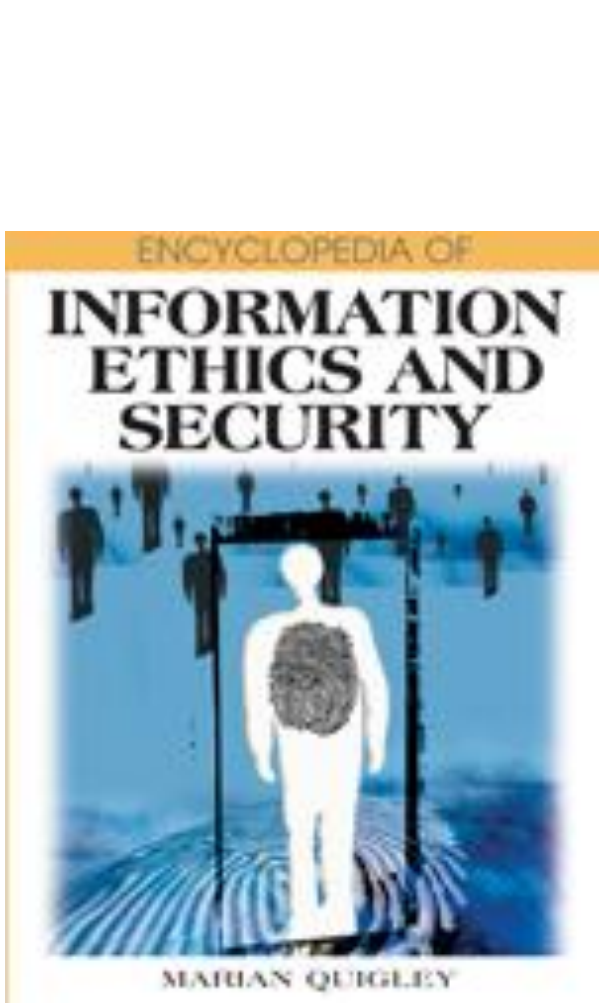

Rapid developments in information and communication technologies have created new security threats along with ethical dilemmas. These developments have been so fast that appropriate security precautions and ethical codes fail to keep pace with the technological developments. In this respect, education of both professionals and ordinary citizens regarding information technology ethics carries utmost importance. Encyclopedia of Information Ethics and Security serves as an authentic and comprehensive reference source on security and ethical issues related to information and communication technologies. The encyclopedia is consisted of 661 pages (+xvii) covering a total of 95 alphabetically ordered chapters on information ethics and security, which are followed by two comprehensive sets of indexes. Each entry is an authoritative contribution followed by in-depth definitions of relevant terminology and acronyms.

The total number of key terms included in the encyclopedia is approximately 700 . The source also includes more than 2000 references to existing literature on ethical and security issues related to information and communication technologies. A total of 148 respected scholars and leading experts all around the world contributed to the source. As indicated in the preface of the encyclopedia by editor, all entries were subjected to an initial double-blind peer review and an additional review prior to acceptance for publication. Chapters mostly have parallel layouts beginning with a clear introduction followed by the theoretical background and the contribution. Each chapter concludes with invaluable ethical implications for the field along with suggestions for further research.

The editor, Marian Quigley (PhD - Monash University, Australia; BA - Chisholm Institute of Technology, Australia; Higher Diploma of Teaching Secondary [Art and Craft]) is a former senior lecturer in the Faculty of Information Technology, Monash University, Australia. She primarily works on the social effects of technology and animation. Her recent publications are Women Do Animate: Interviews with 10 Australian Animators (Insight Publications, 2005) and Information Security and Ethics: Social and Organizational Issues (IRM Press, 2004). The Editorial Advisory Board members who contributed to the work as both reviewers and authors are Kathy Blashki (Deakin University, Australia), Matthew Butler (Monash University, Australia), Heather Fulford (The Robert Gordon University, UK), James E. Goldman (Purdue University, 
USA), Katina Michael (University of Wollongong, Australia) and Bernd Carsten Stahl (De Montfort University, UK).

A diverse set of topics are covered by different entries addressing a wide range of life areas affected by information and communication technologies. These topics include education, the workplace, health, privacy, intellectual property, identity, computer crime, cyber terrorism, equity and access, banking, shopping, publishing, legal and political issues, censorship, artificial intelligence, the environment and communication. As stated by the editor, 'apart from providing information about current and possible future technological developments, the volume contains much thought-provoking material concerning the social and moral implications of information and communication technologies which are of immense importance to us all' (p. xiv).

It is important for ordinary citizens as well as professionals in the field to involve in the debates regarding the transformative effects of information and communication technologies on our lives. In this respect, the book serves as a great reference source for professionals working on information and communication technologies, professionals teaching at educational institutions, both experienced and novice researchers interested in the field, and ordinary citizens who want to be enlightened about ethical practices and implications of information and communication technologies. In addition, moral and social implications of information and communication technologies provided in the source can help educational administrators and policy-makers. Table of contents along with the names of contributors are provided below:

- 3D Avatars and Collaborative Virtual Environments/Koon-Ying Raymond Li, James Sofra, and Mark Power

- Access Control for Healthcare/Yifeng Shen

- Advertising in the Networked Environment/Savvas Papagiannidis and Michael Bourlakis

- Anonymous Peer-to-Peer Systems/Wenbing Zhao

- Argumentation and Computing/Ephraim Nissan

- Argumentation with Wigmore Charts and Computing/Ephraim Nissan

- Artificial Intelligence Tools for Handling Legal Evidence/Ephraim Nissan

- Barriers Facing African American Women in Technology/Jianxia Du, George H. Pate, Deneen Sherrod, and Wei-Chieh Yu

- B-POS Secure Mobile Payment System/Antonio Grillo, Alessandro Lentini, and Gianluigi Me

- Building Secure and Dependable Information Systems/Wenbing Zhao

- Classifying Articles in Information Ethics and Security/Zack Jourdan, R. Kelly Rainer Jr., and Thomas E. Marshall

- Computational Ethics/Alicia I. Ruvinsky

- Computer Ethics and Intelligent Technologies/Yefim Kats

- Computer Worms, Detection, and Defense/Robert J. Cole and Chao-Hsien Chu

- Conflicting Value of Digital Music Piracy/Matthew Butler

- Content Filtering Methods for Internet Pornography/Jengchung V. Chen and ShaoYu F. Huang

- Cyber-Terrorism in Australia/Christopher Beggs

- Data Security and Chase/Zbigniew W. Ras and Seunghyun Im

- Defending against Distributed Denial of Service/Yang Xiang and Wanlei Zhou

- Digital Divide Implications and Trends/Irene Chen and Terry T. Kidd

- Digital Rights Management Metadata and Standards/Jo Anne Cote and Eun G. Park 
- Dilemmas of Online Identity Theft/Omer Mahmood

- Document Security in the Ancient World/Christopher H. Walker

- DRM Practices in the E-Publication Industry/Bong Wee Kiau and Norshuhada Shiratuddin

- Educational Technology Practitioner-Research Ethics/Kathleen Gray

- E-Health and Ensuring Quality/Prajesh Chhanabhai and Alec Holt

- Electronic Signatures and Ethics/A. Srivastava and S. B. Thomson

- Engineering Multi-Agent Systems/Tagelsir Mohamed Gasmelseid

- Ethical Approach to Gathering Survey Data Online/Sophie Nichol and Kathy Blashki

- Ethical Behaviour in Technology-Mediated Communication/Sutirtha Chatterjee

- Ethical Concerns in Computer Science Projects/Alistair Irons and Roger Boyle

- Ethical Debate Surrounding RFID The/Stephanie Etter, Patricia G. Phillips, Ashli M. Molinero, Susan J. Nestor, and Keith LeDonne

- Ethical Dilemmas in Data Mining and Warehousing/Joseph A. Cazier and Ryan C. LaBrie

- Ethical Erosion at Enron/John Wang, James Yao, Richard Peterson, and Zu-Hsu Lee

- Ethical Usability Testing with Children/Kirsten Ellis and Marian Quigley

- Ethics and Access to Technology for Persons with Disabilities/Belinda Davis Lazarus

- Ethics and Perceptions in Online Learning Environments/Michelle M. Ramim

- Ethics and Security under the Sarbanes-Oxley Act/Thomas J. Tribunella and Heidi R. Tribunella

- Ethics Education for the Online Environment/Lori N. K. Leonard and Tracy S. Manly

- Ethics in Software Engineering/Pankaj Kamthan

- Ethics in the Security of Organizational Information Systems/Sushma Mishra and Amita Goyal Chin

- Ethics of AI/Kevin B. Korb

- Fair Use/Pasi Tyrväskylä

- Federal Information Security Law/Michael J. Chapple and Charles R. Crowell

- Formulating a Code of Cyberethics for a Municipality/Udo Richard Averweg

- Hackers and Cyber Terrorists/M. J. Warren

- Homo Electricus and the Continued Speciation of Humans/Katina Michael and M. G. Michael

- IT Security Culture Transition Process/Leanne Ngo

- ICT Leapfrogging Policy and Development in the Third World/Amanda Third and Kai-Ti Kao

- Identity Verification using Resting State Brain Signals/Ramaswamy Palaniappan and Lalit M. Patnaik

- Individual and Institutional Responses to Staff Plagiarism/Carmel McNaught

- Information Ethics as Ideology/Bernd Carsten Stahl

- Information Ethics from an Islamic Perspective/Salam Abdallah

- Information Security and the "Privacy Broker"/Michael Douma and Eduard J. Gamito

- Information Security Policies for Networkable Devices/Julia Kotlarsky, Ilan Oshri, and Corey Hirsch

- Information Security Policy Research Agenda/Heather Fulford and Neil Doherty

- Internet and Suicide/Dianne Currier

- Internet Piracy and Copyright Debates/Paul Sugden

- Internet Research Ethics Questions and Considerations/Elizabeth Buchanan 
- Interviews with Young People using Online Chat/Elza Dunkels and AnnBritt Enochsson

- Intrusion Detection and Information Security Audits/Terry T. Kidd and Robert K. Hiltbrand

- Investigation Strategy for the Small Pedophiles World/Gianluigi Me

- Managed Services and Changing Workplace Ethics/Alan Sixsmith

- Managing the Environmental Impact of Information Technology/Laurel Evelyn Dyson

- Measuring Ethical Reasoning of IT Professionals and Students/Mohammad Abdolmohammadi and Jane Fedorowicz

- Meta View of Information Ethics/Charles R. Crowell and Robert N. Barger

- Mitigation of Identity Theft in the Information Age/Reggie Becker, Mark B. Schmidt, and Allen C. Johnston

- Mobile Agents and Security/Fei Xue

- Modelling Context-Aware Security for Electronic Health Records/Pravin Shetty and Seng Loke

- Moral Rights in the Australian Public Sector/Lynley Hocking

- Multimodal Biometric System/Ajita Rattani, Hunny Mehrotra, and Phalguni Gupta

- Objective Ethics for Managing Information Technology/John R. Drake

- Parental Rights to Monitor Internet Usage/Benjamin J. Halpert

- Patient Centric Healthcare Information Systems in the U.S./Nilmini Wickramasinghe

- Pedagogical Framework for Ethical Development/Melissa Dark, Richard Epstein, Linda Morales, Terry Countermine, Qing Yuan, Muhammed Ali, Matt Rose, and Nathan Harter

- Personal Information Ethics/Sabah S. Al-Fedaghi Pharming Attack Designs/Manish Gupta and Raj Sharman

- Port Scans/Jalal Kawash

- Privacy and Access to Electronic Health Records/Dick Whiddett, Inga Hunter, Judith Engelbrecht, and Jocelyn Handy

- Privacy and Online Data Collection/Cãlin Gurãu

- Privacy in Data Mining Textbooks/James Lawler and John C. Molluzzo

- Protection of Mobile Agent Data/Sheng-Uei Guan

- Rule-Based Policies for Secured Defense Meetings/Pravin Shetty and Seng Loke

- Secure Agent Roaming under M-Commerce/Sheng-Uei Guan

- Secure Automated Clearing House Transactions/Jan Skalicky Hanson and Mark B. Schmidt

- Security Dilemmas for Canada's New Government/Jeffrey Roy

- Security Model for Educational Satellite Networks/Sanjay Jasola and Ramesh C. Sharma

- Security of Communication and Quantum Technology/Gregory Paperin

- Security Protection for Critical Infrastructure/M. J. Warren and T. B. Busuttil

- Spyware/Thomas F. Stafford

- Sustainable Information Society/Ralf Isenmann

- Taxonomy of Computer and Information Ethics/Sabah S. Al-Fedaghi

- Tools for Representing and Processing Narratives/Ephraim Nissan

- Traditional Knowledge and Intellectual Property/Ulia Popova-Gosart

- Universal Internet Access under an Ethical Lens/Alessandro Arbore 